\title{
The Effect of the Practical Intimate Relationship Skills Training (PAIRS) on marital satisfaction and adjustment and sexual function of women living with HIV: a randomized controlled trial
}

Akram kia

Zahra Bayat Jozani

Kourosh Kabir

leili salehi

zohreh mahmoodi ( $\sim$ zohrehmahmoodi2011@gmail.com )

https://orcid.org/0000-0002-7868-6941

Research

Keywords: Marital Satisfaction, Marital Adjustment, Sexual Function, Practical Application of Intimate Relationship Skills, PAIRS

Posted Date: March 17th, 2020

DOI: https://doi.org/10.21203/rs.3.rs-17251/v1

License: (c) (i) This work is licensed under a Creative Commons Attribution 4.0 International License. Read Full License

Version of Record: A version of this preprint was published at HIV \& AIDS Review on January 1st, 2020. See the published version at https://doi.org/10.5114/hivar.2020.101593. 


\section{Abstract}

Background : Considering the role of marital satisfaction and adjustment in family functioning, that can be influenced by specific diseases such as HIV / AIDS, this study was conducted to determine the effect of the Practical Intimate Relationship Skills Training (PAIRS) on marital satisfaction and adjustment and sexual function in women living with HIV (WLHA).

Methods : In a randomized controlled trial 44 WLHA, referred to behavioral disease counseling clinic at Imam Khomeini Hospital, Tehran, Iran, 2019, were randomly divided into intervention and control groups based on four randomized blocks. Eight sessions of educational counseling were provided once a week for both group. At the beginning, at the end and four weeks after the training the Enrich marital satisfaction questionnaire, Spinner marital adjustment and Rosen sexual function questionnaires were completed and analyzed with SPSS-21 software.

Results : This study showed no significant difference between total score of marital satisfaction, marital adjustment and sexual function before the intervention. Rate of marital satisfaction $(P=0.003)$, marital adjustment $(P=0.03)$ and female sexual function $(p<0.001)$ were significantly increased in the intervention group immediately and one month after the intervention. The results also indicated that $77.9 \%$ of the changes in post-test scores of marital satisfaction, $76 \%$ of marital adjustment and $94.9 \%$ of sexual function were related to the intervention effect, demonstrating a sustainable effect of educational intervention $(<0.001)$.

Conclusion : PAIRS can improve marital satisfaction and adjustment, and sexual function in WLHA, and affect quality of family function. Trial registration : Keywords : Marital Satisfaction, Marital Adjustment, Sexual Function, Practical Application of Intimate Relationship Skills; PAIRS

\section{Background}

HIV / AIDS is one of the life threatening viruses of the modern era and it puts high burden on health and economy of countries in terms of high mortality and high cost of care [1]. According to the latest AIDS statistics by United Nations in 2016, of 36.7 million people living with HIV (PLWH) worldwide, $17.8 \%$ are women over the age of 15 [2]. Disease management center of ministry of health in Iran by mid-2017 reported that 36,039 people have been diagnosed with HIV/AIDS [3]. It is a social phenomenon that affects almost all social and economic life dimensions of individuals which causes the quality of marital life of these patients to be reduced along with the fear of disclosure of the disease and its stigma [4]. 
Severe and life-threatening illnesses cause a great deal of stress for the couples [5] which can affect marital satisfaction and consequently marital quality. Marital dissatisfaction is associated with a variety of problems including deep problems in couple relationships and hatred of spouse, annoyance, jealousy, competition, revenge, feeling of being humiliated, lack of confidence and, consequently divorce [6].

Marital Satisfaction is the subjective evaluation and feeling of the person about the marital relationship [7] while marital adjustment is a process in which one adjusts their lifestyle to the others' [8]. Most of these problems are due to the lack of relationship skills between the spouses [9].

Among essential components of effective interventions to increase marital satisfaction and adjustment, it can be referred to training of appropriate relationship skills to spouses, encouraging acceptance of each other and training of realism. One of these intervention programs which is aimed at enriching and enhancing the quality of interpersonal relationships is the Practical Application of Intimate Relationship Skills (PAIRS). This program is based on a psycho-educational event that addresses communication, conflict resolution, self-awareness, and relationship styles [10].

PLWH are one of the most important target groups in the main subject of sexual health, but more concentration is on the risks associated with the transmission of the disease and other aspects of life like sexual satisfaction, as one of the most significant components of these people's quality of life, are ignored which can lead to an increase in the prevalence of the disease [11].

Therefore, with regard to the stated issues and the importance of family health as well as sustainability and given the increasing prevalence of HIV-infected women, it was decided to conduct a study aimed at determining the effect of PAIRS on increasing marital satisfaction, adjustment and sexual function in women living with HIV(WLHA).

\section{Methods}

\section{Design}

The present study was a randomized controlled clinical trial on WLHA referred to behavioral disease counseling clinic in Imam Khomeini Hospital, Tehran, Iran in 2019. Data were collected at baseline and one month follow-up.

\section{Sample size and Sampling methods}

According to the study by Rahmanifar et al. [12], based on marital satisfaction score, using G-Power software based on statistical power of 0.95 and beta of $20 \%$ as well as effect size of 0.9 and given the probability of a $20 \%$ drop, the sample size was determined 50 individuals, 25 participants in each group.

\section{Inclusion criteria}


People were having Iranian nationality, literacy, being in a fixed relationship with an HIV positive partner, with no consuming alcohol, desire to participate in educational courses and not receiving individual counseling services out of educational sessions.

\section{Exclusion criteria}

Individuals with history of hospitalization in psychiatric hospitals, taking any psychotropic drugs, inability to complete the sessions (not attending in two sessions), having no sexual function based on the sexual function questionnaire were excluded.

After identifying the eligible individuals, the study goals were expressed to them and written consent was obtained if they were willing to participate in the study. Participants were then randomly divided into intervention and control groups (with routine care) based on four randomized blocks (six probabilities of $B A B A, B B A A, A B A B, A B A B$, and $B A A B)$. Thus, at the beginning of the study, one of the blocks was selected and four participants were included. Block $A$ was considered as intervention group and block $B$ was considered as control group.

\section{Data collection}

Data were collected using Enrich marital satisfaction questionnaire, Spanier marital adjustment questionnaire, Rosen women's sexual function questionnaire and social- demographic checklist.

\section{The Enrich marital satisfaction}

This questionnaire is an objective self-report tool of 47 questions which was designed by Olson and its reliability was confirmed by Cronbach's alpha coefficient of 0.92 [13]. Correlation coefficient of Enrich questionnaire was reported with family satisfaction scales of 0.41 to 0.60 and life satisfaction scales of 0.32 to 0.41 . All subscales of this questionnaire differentiate satisfied and dissatisfied couples which specifies that it has good criterion validity [14]. Grading for five-item Likert scale varies from score 5 which demonstrates strongly agree to score 1 that denotes strongly disagree. On this scale, the analysis is based on a total of 47 questions. The higher score is the better marital satisfaction while the lower score is the lower marital satisfaction [10].

\section{The Graham B. Spanier (Dyadic Adjustment Scale (DAS))}

This questionnaire has been designed to assess the compatibility between couples or each two individuals who live together. The scale consists of 32 questions in four dimensions including two-person satisfaction, two-person correlation, two-person agreement, and affection. Scoring is based on a five-point Likert scale. Higher scores indicate a better and more consistent relationship. Its validity and reliability 
were evaluated by Sanaei (2000) and overall scale score with Cronbach's alpha of $96 \%$ had good internal consistency [9].

\section{The sexual behavior questionnaire by Rosen et al.}

This questionnaire contains 19 questions on six dimensions of libido, sexual arousal, genital sliders or orgasmic moisture, sexual satisfaction and pain. Scoring the questions is based on a grading system ranged from zero to five and the score of each dimension is then obtained by summing the scores of the questions of the noted dimension (higher score indicates more desirable sexual performance). The questionnaire is a standard general type whose validity and reliability was assessed by Rosen et al. in 2000 [15] and it was approved by Mohammadi et al. in Iran. Coefficients of validity of the test with two bisection and retest methods were reported $78 \%$ and $75 \%$ respectively, while the mentioned coefficients were obtained between $63 \%$ and $75 \%$ for the sub-tests by the bisection method and between $70 \%$ and $81 \%$ by the retest method [16].

\section{Personal - Social checklist}

This checklist includes questions about patient and their spouse as well as their age, level of education, family income, residence, number of children, number of marriages, type of marriage, duration of marriage, use of contraceptive methods and type of contraceptive.

\section{Procedures}

This study was approved by Ethics Committees of Alborz University of Medical Sciences and Health Services with code IR.ABZUMSREC1397.196 and Tehran University of medical Sciences with code IR.TUMS.VCR.REC.1398.470 as well as being registered in Clinical Trial System with code IRCT20160503027728N11.

As we explained selected person randomly divided into intervention and control groups according four randomized blocks. After randomization questionnaires were completed by both groups before the intervention. The obtained scores were considered as base scores for comparison with post-intervention.

Eight sessions of counseling according Practical Intimate Relationship Skills Training, were then offered to intervention group once a week. (table1) 
Table 1

Outline of Training

\begin{tabular}{|llll}
\hline & subject & session \\
\hline $\begin{array}{l}\text { Meeting the members of the group, ice-breaking and warm-up. } \\
\text { Expressing goals and expectations - acceptance and importance } \\
\text { of commitment to change and participation during meetings as } \\
\text { well as introducing PAIRS model and implementation of pretest. }\end{array}$ & $\begin{array}{l}\text { Familiarity with the } \\
\text { rules and expressing } \\
\text { them - creating } \\
\text { confidence and } \\
\text { confidence therapy }\end{array}$ & one \\
$\begin{array}{l}\text { Defining Relationship - Relation between human needs and their } \\
\text { goals of communication - role of good bond in marital } \\
\text { relationships and maintaining self-esteem and individual values } \\
\text { - Relationship characteristics and communication barriers }\end{array}$ & $\begin{array}{l}\text { The importance and } \\
\text { logic of relationship }\end{array}$ & two \\
$\begin{array}{l}\text { Designing and planning a new way of communicating for } \\
\text { couples - active listening - training of self-expression and } \\
\text { effective dialogue }\end{array}$ & Creating link & three \\
$\begin{array}{l}\text { Effective verbal and nonverbal dialogue between couples and } \\
\text { training in problem solving }\end{array}$ & Problem Solving & four \\
$\begin{array}{l}\text { Awareness of each person and their spouse mental imagination } \\
\text {-avoiding misunderstandings -expressing male and female } \\
\text { differences - revealing hidden expectations }\end{array}$ & Making contract: & five \\
\hline $\begin{array}{l}\text { Training of sexual skills (Sexual Attitudes and Behaviors as well } \\
\text { as improving sexual and emotional relationships) }\end{array}$ & $\begin{array}{l}\text { Training sexual skills } \\
\text { imagination and } \\
\text { expectations }\end{array}$ & six \\
$\begin{array}{l}\text { regulating the dimensions of unity and adaptation to maintain } \\
\text { family function }\end{array}$ & $\begin{array}{l}\text { Unity and adaptation } \\
\text { in the family }\end{array}$ & seven \\
$\begin{array}{l}\text { Conclusion - Introducing some of the functional books in the } \\
\text { program and implementation of post-test }\end{array}$ & $\begin{array}{l}\text { Concluding and } \\
\text { ending session }\end{array}$ & eight \\
\hline
\end{tabular}

\section{Intervention}

Both groups received 8 sessions counseling. The control group received counseling sessions according to the protocol of the behavioral disease counseling clinic in accordance with the national protocol of AIDS.

The intervention group, in addition to the routine counseling sessions in the control group, received 8 sessions of 45-60 minutes of training for intimate relationship skills were provided for intervention group (Table 1). 
Table 2

Demographic characteristics of the participants in the intervention and control groups

\begin{tabular}{|c|c|c|c|c|}
\hline & & Intervention ( $\mathrm{N}=22)$ & Control $(\mathrm{N}=22)$ & $\mathrm{P}$ \\
\hline & & $\mathrm{N}(\%)$ & $\mathrm{N}(\%)$ & \\
\hline Qualitative variable & & & & \\
\hline Number of child & 1 or 2 & 13(59.1) & $15(68.2)$ & 0.6 \\
\hline & 3 and more & $2(9.1)$ & $4(18.2)$ & 0.6 \\
\hline & Without child & $7(31.8)$ & $3(13.6)$ & 0.6 \\
\hline Number of marriage & 1 & 13(59.1) & 18(81.8) & $0.2^{*}$ \\
\hline & 2 & $8(36.4)$ & $4(18.2)$ & $0.2^{*}$ \\
\hline & 3 & $1(4.5)$ & 0 & $0.2^{*}$ \\
\hline Type of Marriage & permanent & 17(77.3) & 19(86.4) & $0.4^{*}$ \\
\hline & brief & $5(22.7)$ & $3(13.6)$ & $0.4^{*}$ \\
\hline Wife education & Primary & $2(9.1)$ & $2(9.1)$ & $0.8^{*}$ \\
\hline & Secondary & $6(31.8)$ & $6(27.3)$ & $0.8^{*}$ \\
\hline & Guidance & $2(13.6)$ & $2(9.1)$ & $0.8^{*}$ \\
\hline & Diploma & $10(45.5)$ & $10(45.5)$ & $0.8^{*}$ \\
\hline & Academic & 0 & $2(9.1)$ & $0.8^{*}$ \\
\hline Husband education & Primary & $7(31.8)$ & $3(13.6)$ & $0.07 *$ \\
\hline & Secondary & $5(22.7)$ & 0 & $0.07 *$ \\
\hline & Guidance & $1(4.5)$ & 0 & $0.07 *$ \\
\hline & Diploma & $7(31.8)$ & $12(54.5)$ & $0.07^{\star}$ \\
\hline & Academic & $2(9)$ & $7(31.8)$ & $0.07 *$ \\
\hline Wife job & Household & 18(81.8) & $15(68.2)$ & $0.2^{*}$ \\
\hline & Employee & $4(18.2)$ & $4(18.2)$ & $0.2^{*}$ \\
\hline & Azad & 0 & $3(13.6)$ & $0.2^{*}$ \\
\hline Quantitative variable & & Mean \pm sd & Mean $\pm s d$ & $0.2^{*}$ \\
\hline Marriage length & & $12.8 \pm 11.3$ & $9.1 \pm 5.3$ & $0.2^{\star \star}$ \\
\hline Marriage age & & $23.5 \pm 10.6$ & $28.2 \pm 10.6$ & $0.08^{* *}$ \\
\hline
\end{tabular}




\begin{tabular}{|c|c|c|c|}
\hline & Intervention ( $\mathrm{N}=22)$ & Control (N=22) & $\mathrm{P}$ \\
\hline & $\mathrm{N}(\%)$ & $\mathrm{N}(\%)$ & \\
\hline Women age & $37.5 \pm 6.2$ & $36.3 \pm 8.9$ & $0.6^{* *}$ \\
\hline Husband age & $41.5 \pm 10.7$ & $44.4 \pm 9.2$ & $0.3^{\star \star}$ \\
\hline
\end{tabular}

The content of the sessions was approved by group of experts in field of HIV. Questionnaires were completed by participants at the beginning, at the end, and four weeks after the sessions. Participation in the study was voluntary and participants could be excluded from the study at any time and it would not prevent them from receiving usual services.

Sixty people met the inclusion criteria but ten people were excluded from the research due Declined to participate, and fifty people randomizes in two groups( 25 people in each group).During the study three people of intervention group Discontinued intervention and in control group one person Lost to follow-up and two person Discontinued intervention, finally the information of 44 people was analyzed in both groups. (figure1)

Figure1: consort Flow Diagram

Interviews were held in the conference room of the clinic to avoid any relationships between the two groups as much as possible

Interviews were held in the conference room of the clinic to avoid any relationships between the two groups as much as possible

\section{Statistical analysis}

Data were entered into SPSS-21 software and Kolmogorov-Smirnov test was used to confirm the assumption of normality of the data.

Data were analyzed using descriptive statistics, Chi-Square and independent t-test, and variance analysis with repeated measures.

\section{Outcome measures}

Three main outcomes include: marital satisfaction, adjustment and sexual function in current study were assessed.

\section{Results}


The study was conducted with the participation of 44 WLHA including 22 individuals in each group. The mean \pm SD of the women age in the intervention group was $37.5 \pm 6.5$ and it was $36.3 \pm 8.9$ in the control group $(P=0.6)$. The two groups did not differ in terms of individual and social variables such as average age of participants and their spouse, educational level of participants and their spouse, and occupation of participants and their spouse (Table 2).

Table 3

Comparison of total mean score of marital satisfaction, marital adjustment and sexual function before, immediately after and one month after intervention in intervention and control groups

\begin{tabular}{|c|c|c|c|c|c|c|}
\hline & group & $\begin{array}{l}\text { Before } \\
\text { intervention } \\
\text { mean } \pm \text { sd }\end{array}$ & $\begin{array}{l}\text { After } \\
\text { intervention } \\
\text { mean } \pm \text { sd }\end{array}$ & $\begin{array}{l}\text { One month } \\
\text { after } \\
\text { intervention } \\
\text { mean } \pm \text { sd }\end{array}$ & $\begin{array}{l}\text { Repeated } \\
\text { measures } \\
\text { P-value in } \\
\text { each } \\
\text { group }\end{array}$ & $\begin{array}{l}\text { Repeated } \\
\text { measures } \\
\text { P-value } \\
\text { between } \\
\text { group }\end{array}$ \\
\hline \multirow{2}{*}{$\begin{array}{l}\text { Marital } \\
\text { Satisfaction }\end{array}$} & Intervention & $122.1 \pm 17.1$ & $132.6 \pm 16.0$ & $131.6 \pm 13.3$ & 0.033 & \multirow[t]{2}{*}{0.003} \\
\hline & control & $123.8 \pm 25.0$ & $121.6 \pm 23.4$ & $119.6 \pm 23.1$ & 0.932 & \\
\hline \multicolumn{2}{|c|}{ Independed t-test } & 0.79 & 0.04 & \multicolumn{2}{|l|}{0.03} & \\
\hline \multirow{2}{*}{$\begin{array}{l}\text { Marital } \\
\text { adjustment }\end{array}$} & Intervention & $89.2 \pm 9.7$ & $98.5 \pm 19.7$ & $98.8 \pm 17.3$ & 0.017 & \multirow[t]{2}{*}{0.03} \\
\hline & control & $90.5 \pm 25.7$ & $87.7 \pm 24.5$ & $88.3 \pm 24.8$ & 0.834 & \\
\hline \multicolumn{2}{|c|}{ Independed t-test } & 0.85 & 0.04 & 0.04 & & \\
\hline \multirow{2}{*}{$\begin{array}{l}\text { Sexual } \\
\text { function }\end{array}$} & Intervention & $47.0 \pm 16.1$ & $69.6 \pm 9.4$ & $56.4 \pm 6.9$ & 0.009 & \multirow[t]{2}{*}{0.000} \\
\hline & control & $45.7 \pm 14.4$ & $44.3 \pm 14.5$ & $44.8 \pm 14.1$ & 0.051 & \\
\hline \multicolumn{2}{|c|}{ Independed t-test } & 0.78 & 0.000 & 0.002 & & \\
\hline
\end{tabular}

Based on the obtained results, there was no significant difference between two groups before intervention, in terms of the mean scores of marital satisfaction $(P=0.79)$, marital adjustment $(P=0.84)$ and sexual function $(P=0.78)$ and the two groups were homogeneous in terms of investigated variable status (Table 3).

Repeated measures test was used in control and intervention groups before, immediately after and one month after intervention in order to evaluate changes in overall score of marital satisfaction, marital adjustment and sexual function. The assumption of homogeneity of variances was evaluated using the Levene test and the result indicated their homogeneity $(P>0.05)$.

Test result of repeated measures test indicated the effect of intervention over time on the mean score of marital satisfaction $(P=0.003)$, marital adjustment $(P=0.03)$ and sexual function $(P<0.001)$ and there was a significant difference between the two groups so that the mean score of marital satisfaction in the intervention group significantly increased compared to the control group over time but a decreasing trend was observed in the control group. 
In the intervention group, one month after the intervention, the mean score of marital satisfaction decreased slightly relative to immediately after the intervention which indicates the need for longer counseling interventions for further sustainability of consultation effectiveness.

The mean score of marital adjustment was significantly increased in the intervention group compared to the control group over time. However, there was a decreasing trend in the control group. Regarding the sexual function score, the mean score in the intervention group increased significantly over time compared to the control group, whereas in the control group, there was a decreasing trend over time (Table 3).

According to the results of One-Way Analysis of Variance with repeated measure (ANOVA), the effect size on marital satisfaction is 0.779 . In other words, $77.9 \%$ of the differences in post-test scores of marital satisfaction were related to the effect of intervention. The effect size on marital adjustment was 0.763 , which means that $76.3 \%$ of the differences in post-test scores were related to the intervention effect.

Also, the effect size on sexual function was 0.949 , which demonstrates that $94.9 \%$ of the differences in sexual function post-test scores were related to the intervention effect, indicating a lasting effect of educational intervention (Table 4).

Table 4

intergroup effects of total score ANOVA with repeated measure of marital satisfaction, marital adjustment and sexual function in intervention and control groups

\begin{tabular}{|lllllll|}
\hline variable & $\begin{array}{l}\text { sum of } \\
\text { squares }\end{array}$ & Mean Square & df & F & P & $\begin{array}{l}\text { Partial Eta } \\
\text { Squared }\end{array}$ \\
\hline $\begin{array}{l}\text { Marital } \\
\text { Satisfaction }\end{array}$ & 2068754.735 & 2068754.735 & 1 & 1988.009 & 0.000 & 0.779 \\
\hline $\begin{array}{l}\text { Marital } \\
\text { adjustment }\end{array}$ & 1053417.700 & 1053417.700 & 1 & 1021.556 & 0.000 & 0.763 \\
\hline Sexual function & 309522.944 & 309522.944 & 1 & 745.822 & 0.000 & 0.949 \\
\hline
\end{tabular}

\section{Discussion}

The study showed that the mean score of marital satisfaction changed over time in both groups. An increase in the obtained scores of the intervention group and a decrease in scores of the control group was noticed by comparing the means. Also, $77.9 \%$ of the differences in the post-test scores of marital satisfaction were related to the effect of the intervention which indicates the sustainable effect of the educational program intervention. This finding is in line with the results of studies by Moeni et al. (2016) who found that relationship skills' training improves women's marital satisfaction score [17].

In their study on women with cancer, Taheri et al. found out that $71 \%$ of the changes in the intervention group were related to the effect of training of intimate relationship skills [18]. These outcomes are also 
confirmed in the studies by Bahari et al. [19], Momeni et al. [20], Sanagooei et al. [21], Abbasi et al. [22], Cobb and Sullivan [23]. PAIRS can help in continuity the marriage and ultimately reduce marital conflicts which leads to more intimacy and satisfaction between couples. This approach addresses the basic needs of the family, such as love, affection, belonging, and commitment. All of which can increase the quality of life and satisfaction.

The aim of PAIRS is achieving cohesion, empathy, and intimacy in couples' relationships. It teaches skills to build up and maintain intimate relationships to reach this purpose. Finally, it applies practical knowledge, strategies and attitudes aimed at enabling participants to build up relationships that spouses can live together with joy [18].

Based on the results of the study, the mean score of marital adjustment changed over time in both groups. An increase in the mean score in the intervention group relative to the control group was observed by comparing the two groups. Also, according to the outcomes, $76.3 \%$ of the differences in post-test scores of marital adjustment were related to the effect of the intervention, which indicates the sustainable effect of the educational intervention.

The effect of group training on the PAIRS in enhancing couples' satisfaction, adjustment, positive feelings and marital intimacy was investigated in a study by Mahmoudi which showed that marital adjustment increased in the intervention group after training.

The effect of the PAIRS in the post-test phase was also reported $65 \%$ for marital adjustment [24]. The results of the present study are consistent with the studies by Taheri et al [18], Abbasi et al [22], Gasbarrini et al [25] and Williamson et al [26].

Marital adjustment is a multidimensional term that describes multiple levels of marriage and it is a process that occurs throughout the lives of couples since it requires the adaptation of tastes, the recognition of personality traits, the development of behavioral rules, and the formation of behavioral patterns. Therefore, marital adjustment is an evolutionary process between husband and wife.

The principles taught in the PAIRS approach and addressed in this intervention were noted by Halford [27], in order to have realistic expectations, flexibility of couples, and training to maintain a positive attitude about themselves, others, and life.

Behavioral techniques are used in this approach to teach skills to achieve intimacy in relationships, assuming that adaptive behavior is learned through imitation, pattern, and repetition. Through a variety of activities, the program enhances individual self-awareness in order to influence attitudinal change and enhances conflict resolution and communication skills [27].

Based on the findings, the overall mean score of sexual function of women changed over time in both groups and by comparing between groups, we found an increase in the performance score in the intervention group and a decrease in the opposite group. Also, $94.9 \%$ of the differences in post-test scores on sexual performance were related to the effect of the intervention which indicates the sustainable effect 
of the educational intervention. The results of the present study are consistent with the studies conducted by Khamseh et al. [28], Moradi et al. [29] and Korporaal et al. [30]. In their studies on healthy and diabetic women, they reported the effectiveness of PAIRS on sexual function.

In this program, couples are trained to correct their behavior through increased security and support, availability, responsiveness to spouse needs and developing safe behaviors, methods of enhancing intimacy and relationship, training of proper relationship skills and having a desired sex.

In addition, they should enhance their verbal and nonverbal interactions, show sexual self-esteem including touching, embracing and kissing in their relationship with their spouse, and express their thoughts, feelings, needs and desires and have more physical closeness [31]. PAIRS is a training program that offers a comprehensive system for raising people's awareness and developing their abilities to build and maintain enjoyable intimate relationships [32]. One of the categories of the PAIRS program, which is emphasized for creativity and intimacy, is the ability of talking and problem-solving in a way that couples listen to each other empathically, express discomfort without defense, acknowledge each other's differences and resolve misunderstandings so that they can meet each other's core needs such as sexuality, intimacy, closeness, etc.

In this way, couples can express their thoughts, feelings, needs as well as desires and become more physically close. Therefore, being aware of their spouse's needs and having the ability of talking and solving problem can lead to greater satisfaction, adaptation, and sexual function [33].

An important point of present research which separates it from other studies is the study population. Based on the reviews, no studies have been found to evaluate women Acquired Immune Deficiency Syndrome (AIDS) in Iran.

According to the expressed contents about the requirement to take practical measures for preventing the spread of the disease and adherence of patients to treatment, the necessity of such educational interventions is more proposed for this vulnerable group than ever before.

\section{Conclusions}

Based on the results of the study, implementation of PAIRS improves marital satisfaction and adjustment and sexual function in women with Acquired Immune Deficiency Syndrome (AIDS).

Given the multiple individual - social problems of this vulnerable group of society, who require the support and empathy of their families, especially their spouses, providing practical program that strengthen and consolidate their marital relationships is very useful and it can be effective in adhering to treatment and preventing the spread of the disease.

\section{Limitations of the study}


In the present study, a training program was provided only for women with Acquired Immune Deficiency Syndrome (AIDS) and their spouses did not participate in the noted programs. According to the culture of the country, talking about sexual issues is accompanied with limitations and hardships, which can be one of the biggest constraints of researchers in educating spouses of the mentioned women.

\section{Declarations}

\section{Consent for publication}

The authors declare they have Consent for publication

\section{Acknowledgments}

the present study is the result of a Master's Degree of counseling in midwifery. Hereby, authors would like to appreciate the Honorable Vice Chancellor of Research in Alborz University of Medical Sciences, behavioral disease counseling center of Imam Khomeini Hospital-Tehran due to their scientific and material support as well as the staff of behavioral disease counseling center of Imam Khomeini hospital and all those who participated in this study.

\section{Authors' contributions}

AK: collected the data and statistical analysis and write the manuscript. ZB: helped in collection the data and analyzing.ZM has supervised the study; contributed to the study design and conducted the analysis and write the manuscript KK: analyzed the data and draft the manuscript. LS: helped as Scientific Adviser. the author(s) read and approved the final manuscript

\section{Ethics approval and consent to participate}

\section{Informed consent was obtained from all individual participants included in the study.}

An ethics code was obtained from Alborz University of Medical Sciences and Health Services with code IR.ABZUMSREC1397.196 and Tehran University of medical Sciences with code IR.TUMS.VCR.REC.1398.470 as well as being registered in Clinical Trial System with code IRCT20160503027728N11

\section{Funding}

This study conducted without any funding 


\section{Availability of data and materials}

The current study datasets and analysis sheets are available and will be provided due to reasonable request

\section{Competing interests}

The authors declare that they have no competing interests

\section{Abbreviations}

AIDS = Acquired Immune Deficiency Syndrome

HIV = human immunodeficiency viruses

WLHA = women living with HIV

PAIRS $=$ Practical Intimate Relationship Skills Training

Figures 


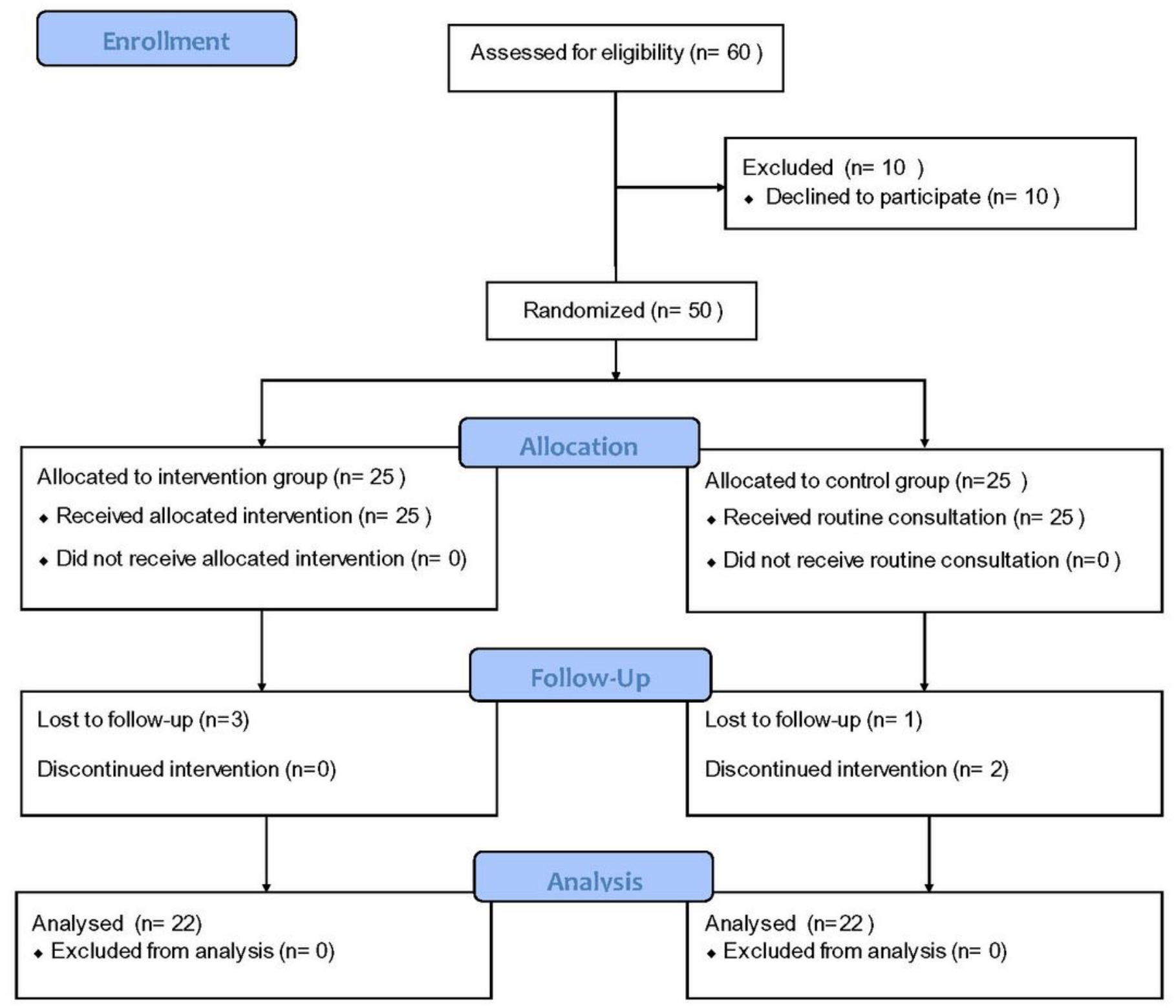

Figure1: consort Flow Diagram

Figure 1

consort Flow Diagram 